\title{
Triband Compact Antenna for Multistandard Terminals and User's Hand Effect
}

\author{
M. Koubeissi, M. Mouhamadou, C. Decroze, D. Carsenat, and T. Monédière \\ XLIM Laboratory, University of Limoges, 123 Avenue Albert THOMAS, 87065 Limoges Cedex, France \\ Correspondence should be addressed to M. Koubeissi, majed.koubeissi@xlim.fr
}

Received 5 June 2009; Revised 22 October 2009; Accepted 7 December 2009

Recommended by Mohammod Ali

\begin{abstract}
A novel compact wideband triband antenna for mobile terminals based on PIFA element is proposed. The antenna operates at the following frequency bands: Wireless-LAN $802.11 \mathrm{~b}$, g, a and WiMAX 3.5 GHz. The antenna was studied by means of numerical simulations as well as the ground plane dimensions and user's hand effects. The overall size of the radiating element which is $1.8 \times 1.54 \times 9 \mathrm{~mm}$ makes it suitable for use in terminals and appropriate to integrated as an internal laptop antenna. The measured bandwidths show that the proposed antenna can cover three bands $(2.39-2.48 \mathrm{GHz}),(3.36-3.76 \mathrm{GHz})$, and $(4.7-6.3 \mathrm{GHz})$ and the total efficiency is better than $90 \%$. The radiation patterns of the antenna were carried in an anechoic chamber and are given to demonstrate the antenna's performance.
\end{abstract}

Copyright (C) 2009 M. Koubeissi et al. This is an open access article distributed under the Creative Commons Attribution License, which permits unrestricted use, distribution, and reproduction in any medium, provided the original work is properly cited.

\section{Introduction}

Nowadays, modern mobile handsets are becoming more and more complex devices. Indeed, the modern handsets should be miniature in size and provide access to different communication standards throughout a broadband in order to obtain high data rates without increasing the transmitted power. In fact, due to the increase of wireless standards, there is need of multiband antennas implementation on the terminals.

In this paper, we present a tri-band antenna for the desired Wireless-LAN and WiMAX applications. The antenna must be integrated in such a way to take up a very small space on the printed circuit board. Due to these requirements which are multiband system and reduced size, a planar PIFA (printed inverted F antenna) is an attractive candidate [1-4]. Indeed, the PIFAs have low profiles, good radiation characteristics, and acceptable bandwidth. Thus, a miniaturized tri-band and single probe fed PIFA that operates in the $2.4-2.48 \mathrm{GHz}, 3.4-3.6 \mathrm{GHz}$, and $4.9-6 \mathrm{GHz}$ frequency bands is designed. The simulated results of the fabricated proposed antenna are validated by the measured one. The simulations were performed thanks to CST MS based on the finite integration method. This work was supported in part by the French Research Agency project called ORIANA [5].

\section{Antenna Design}

The PIFA structure guarantees the quarter wavelength resonance frequency and then an operating frequency band. The PIFA is fed by a strip while another is used to ground it. It is undoubtedly true that PIFA offers higher-order resonance frequencies. It is not only hard to control the higher-order frequency resonance but even worse. Both the radiation performance and return loss are inefficient to be used at these higher frequencies. The key to obtain additional resonance frequencies should be the PIFA's structure modification [68]. In fact, different shapes and locations of slots can be added to the PIFA in order to achieve additional resonance frequencies. Indeed, when a J-shaped slot is properly inserted on the conducting patch of the PIFA, a second resonance frequency appeared. Following this J-shaped slot, a shift in the PIFA first resonance frequency will occur. Therefore, the first and second frequencies can be altered by varying the size of the PIFA and the J-slot because the one reactively loads another which does not allow them to operate as two independent antennas. 


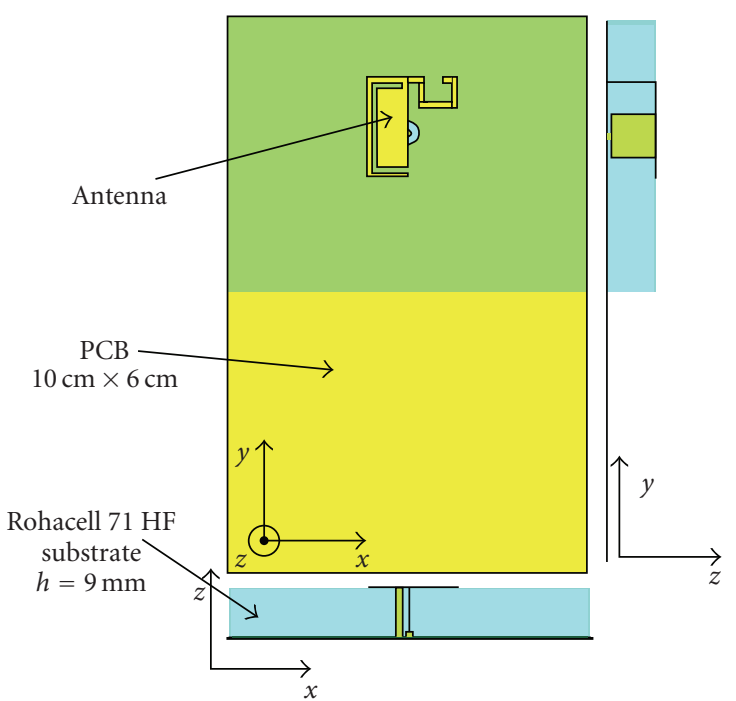

FIGURE 1: Top and side views of the tri-band antenna.

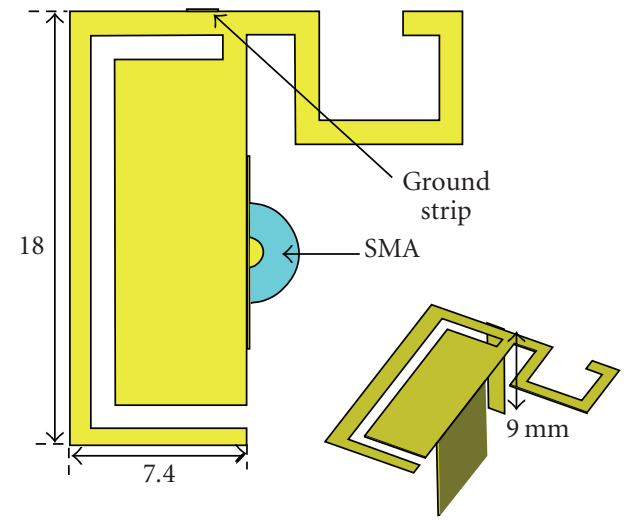

FIgure 2: Triband radiating element with an SMA connector (dimensions are in $\mathrm{mm}$ ).

For the third wide frequency band $(4.9-6 \mathrm{GHz})$, an additional resonance frequency appeared when a meander line is added to the overall structure.

The tri-band structure, shown in Figure 1, may be probe fed by a $50 \Omega$ SMA connector for the different standards application and is shown in Figure 1. The size of the ground plane is $100 \mathrm{~mm} \times 60 \mathrm{~mm}$ and it is considered as a circuit board of a practical handset where the metallic parts are placed on the surface of a Rohacell $71 \mathrm{HF}$ substrate with relative permittivity 1.09 . The thickness of the metallic parts is $0.1 \mathrm{~mm}$.

The geometry of the resultant multiband PIFA is shown in Figure 2. Since this proposed antenna has multiple design parameters such as the PIFA's height and dimensions, the slot, and line width, CST Microwave Studio (CST MS) is used in order to obtain optimum antenna performances. In this case, the antenna element dimensions are shown in Figure 2.
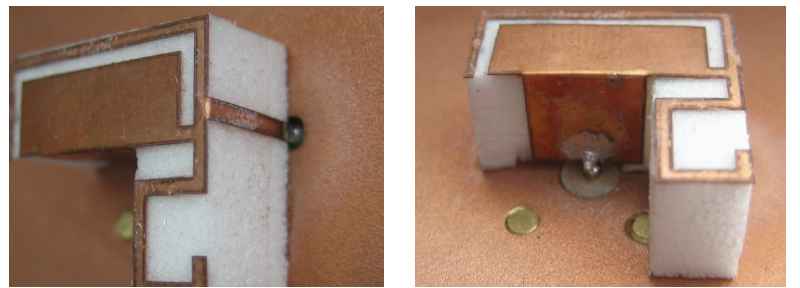

Figure 3: Photos of the tri-band antenna showing the ground and feeding strips.

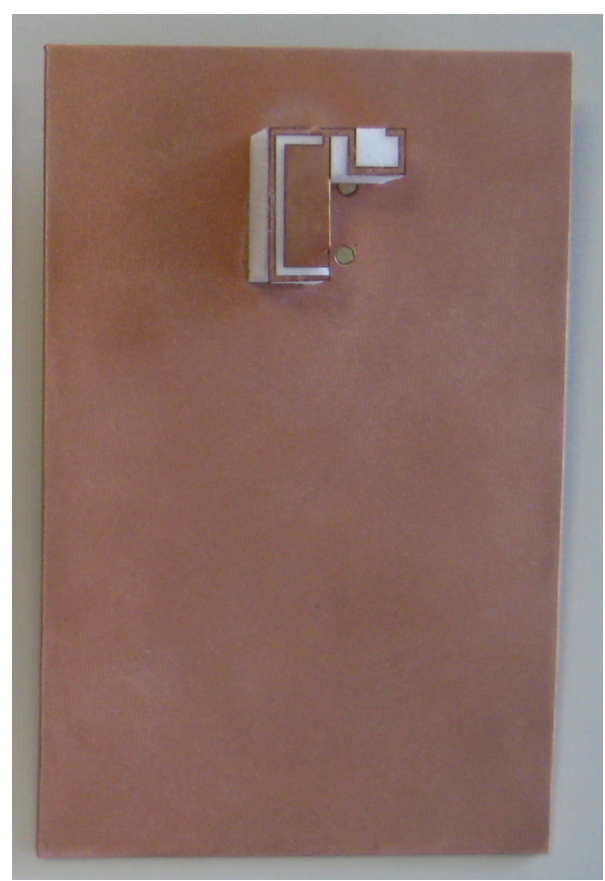

Figure 4: Photos of the tri-band antenna with a $10 \mathrm{~cm} \times 6 \mathrm{~cm}$ PCB.

\section{Simulation and Experimental Results}

3.1. S parameters. The simulations have shown that this radiating element can be excited at three resonance frequencies. The first resonance frequency is mainly governed by the PIFA dimensions; the second frequency is mainly due to the J-shaped open-end arm while the last corresponds to the meander line length. Beside these design parameters and the antenna height, the ground plane dimensions influence the input matching. The proposed tri-band antenna is entirely manufactured through a $0.1 \mathrm{~mm}$ thickness copper sheet and by folding the ground and feed arms of the PIFA.

The antenna prototype is shown in Figures 3 and 4 . The experimental results are presented and compared to the simulated ones where the $S$ parameters are shown in Figure 5. There is a good impedance matching and broad bandwidths and the experimental results agree well with the simulated ones. As seen in Figure 5, the return loss of the multistandard antenna is lower than $-10 \mathrm{~dB}$ which clearly demonstrates the ability of the tri-band proposed antenna. So, the three measured impedance matching bandwidths at 


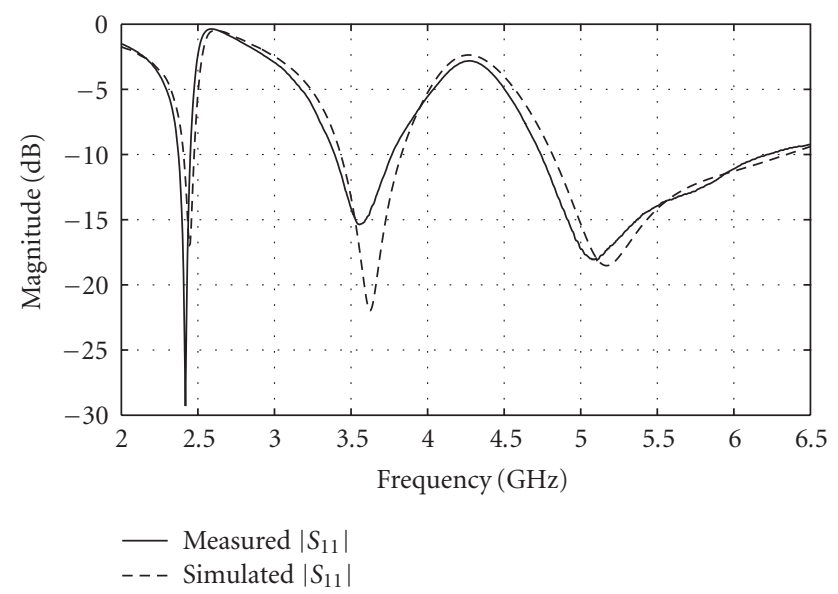

FIGURE 5: Simulated and measured reflection coefficient of the triband antenna.

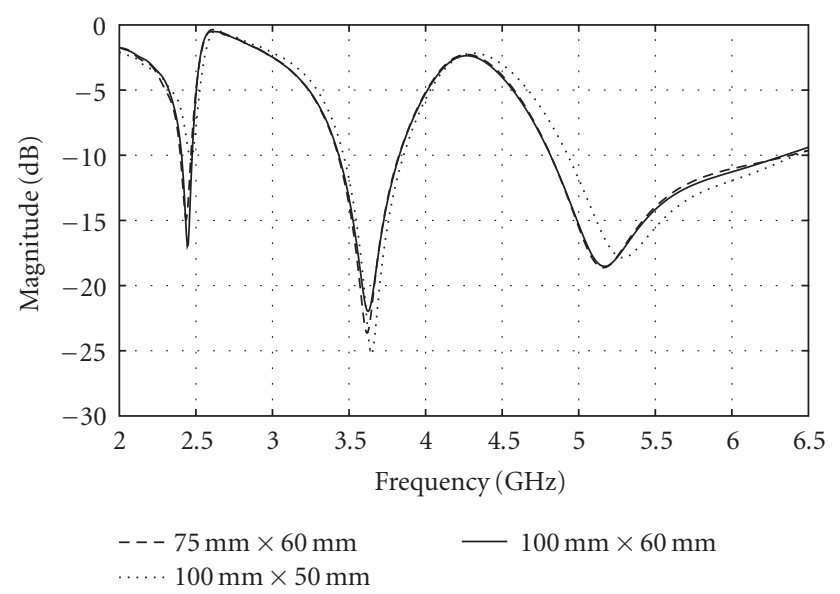

Figure 6: Simulated reflection coefficient for different PCB dimensions.

$\mathrm{S} 11<-10 \mathrm{~dB}$ are $80 \mathrm{MHz}(2.39-2.48 \mathrm{GHz}), 400 \mathrm{MHz}$ (3.36$3.76 \mathrm{GHz})$, and $1.6 \mathrm{GHz}(4.7-6.3 \mathrm{GHz})$, covering WiFi and WiMAX bands.

3.2. Ground Plane and Antenna Height Effects. Now, the PCB ground plane length and width are varied to investigate the influence of the ground plane current distribution on the antenna characteristics. Figure 6 shows the influence of the ground plane dimensions on the antenna reflection coefficient. It can be noted from Figure 6 that the PCB dimensions have only a slight effect on the two high resonances. On the other hand, the PCB width affects the low resonance frequency where lowering the PCB width will increase the first resonance frequency of the antenna.

One is led to conclude that the resonance frequencies depend on the current distribution on the ground plane and then on its dimensions leading to set these dimensions from the beginning. It is clear that these three resonance frequencies can be found by optimising the antenna design

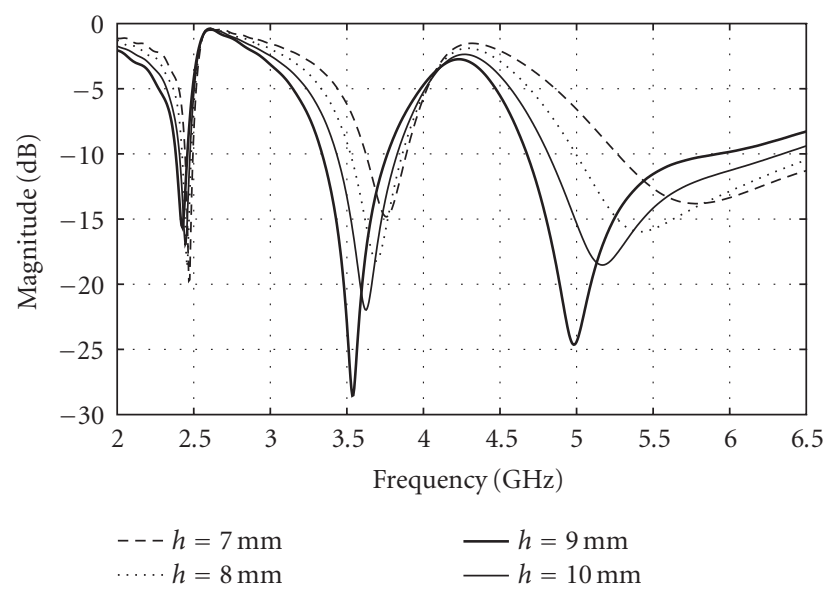

Figure 7: Simulated reflection coefficient for different antenna heights.

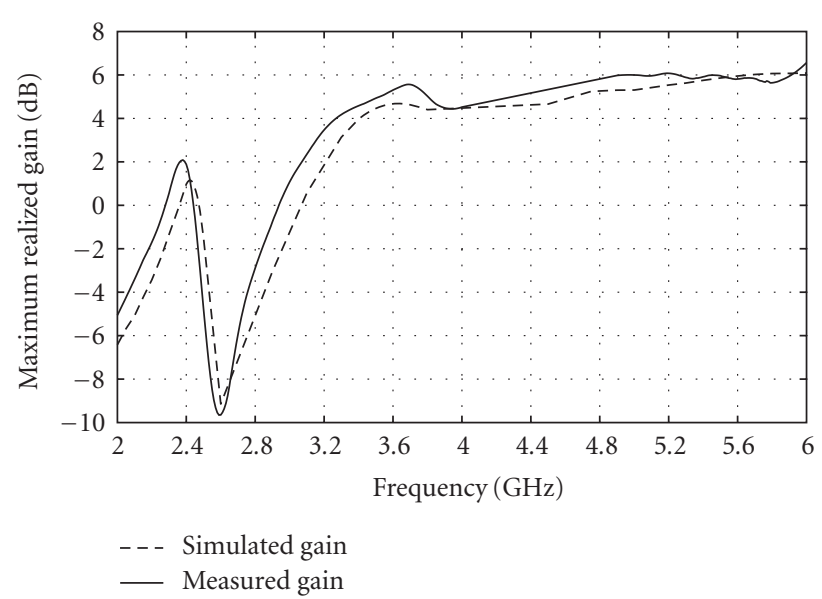

FIgURE 8: Simulated and measured maximum gain of the tri-band antenna.

parameters whatever the $\mathrm{PCB}$ dimensions and then the antenna application.

Several parameters can affect the three resonance frequencies, in particular the antenna height. Figure 7 shows the influence of the antenna height on the antenna reflection coefficient where only the antenna height is modified without having done any optimization.

It is obvious that the antenna height has an important effect on the quality factor and bandwidths. As the antenna height is decreased, the quality factor increases and the bandwidths become narrower. It should be noted that the antenna height has a slight effect on the resonance frequencies.

In fact, these results are particularly interesting. They show a possible height decrease to $7 \mathrm{~mm}$ or less but to the detriment of the bandwidth.

Also, it is well worth noting that the return loss characteristics, in particular its minimum, do not change if the PIFA radiating element is moved to the left or right upper 


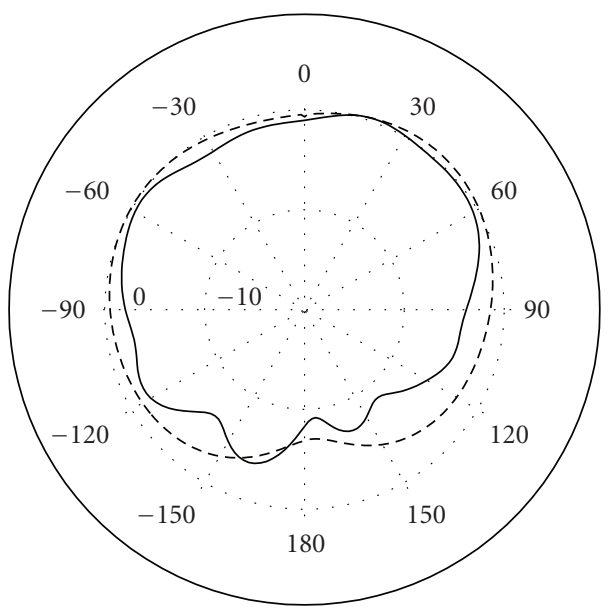

(a)

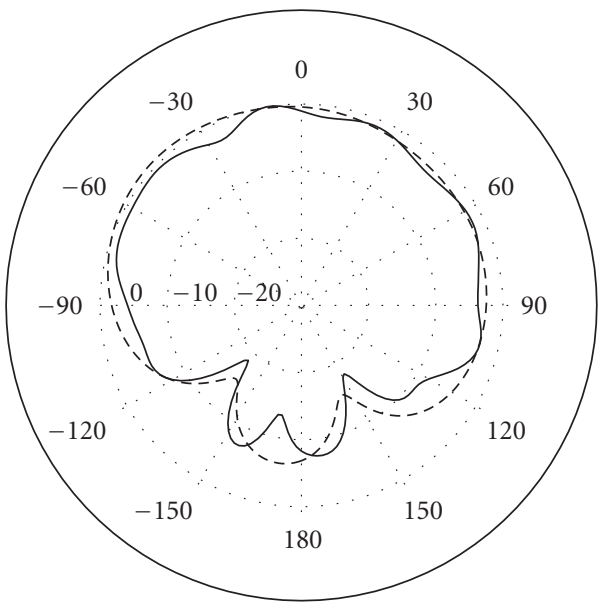

(b)

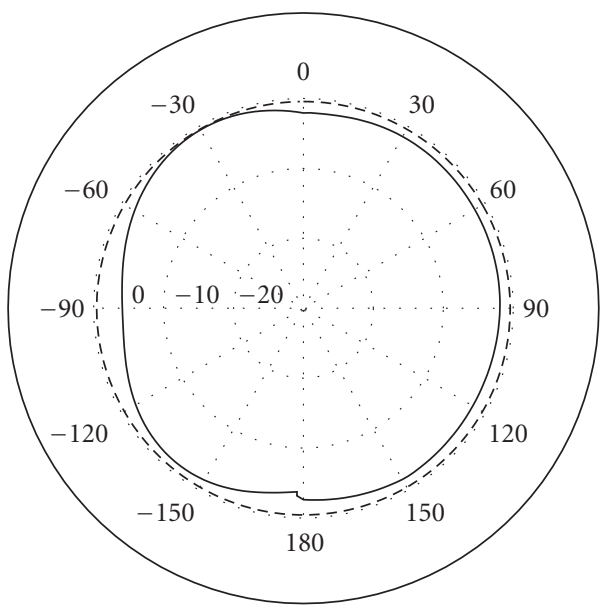

(c)

FIGURE 9: Measured (solid line) and simulated (dashed line) radiation patterns at $2.44 \mathrm{GHz}$ : (a) $x-z$ plane, (b) $y-z$ plane, and (c) $x-y$ plane.

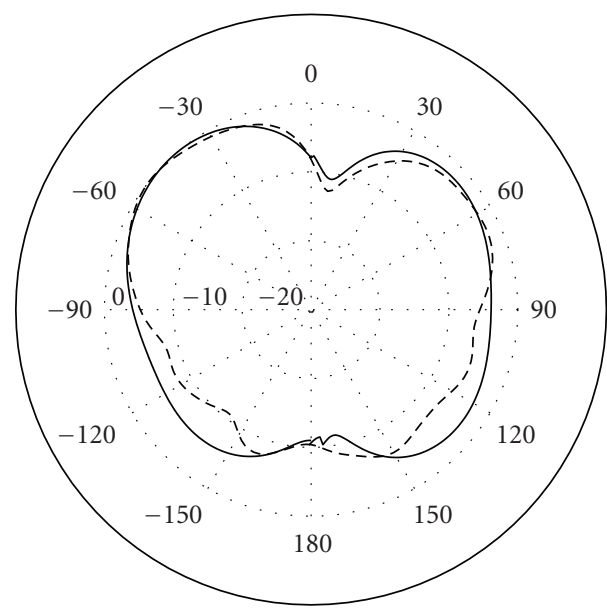

(a)

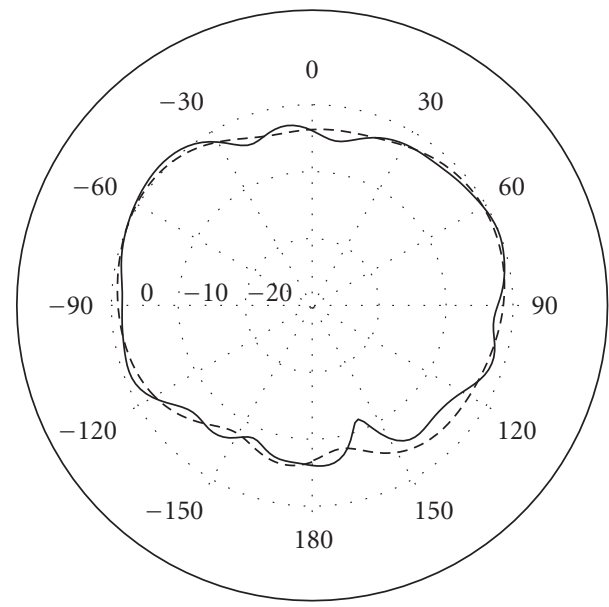

(b)

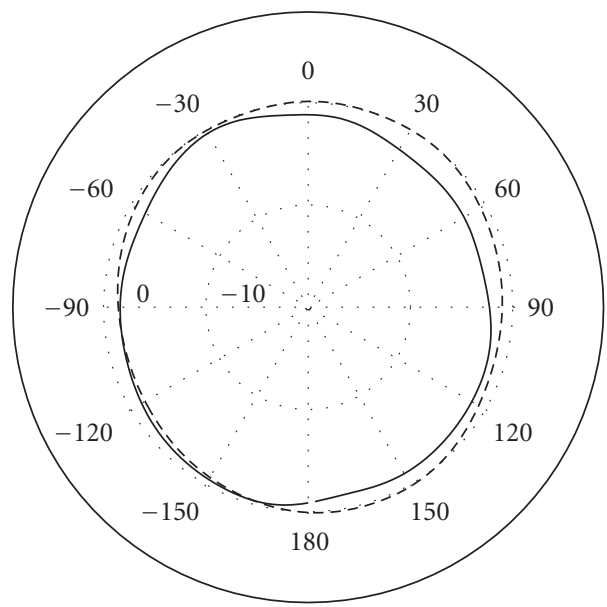

(c)

FIgURE 10: Measured (solid line) and simulated (dashed line) radiation patterns at $3.5 \mathrm{GHz}$ : (a) $x-z$ plane, (b) $y$ - $z$ plane, and (c) $x-y$ plane. 


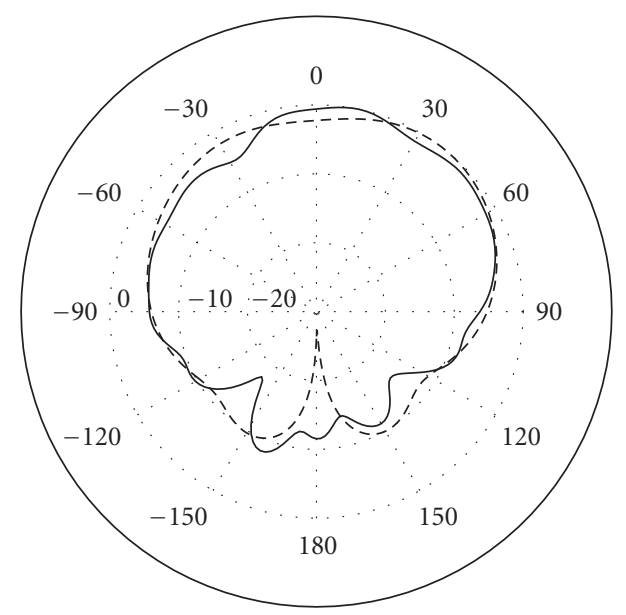

(a)

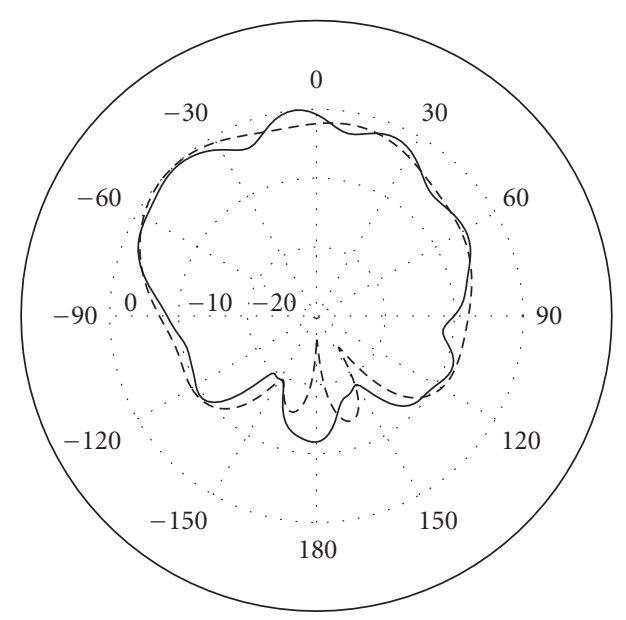

(b)

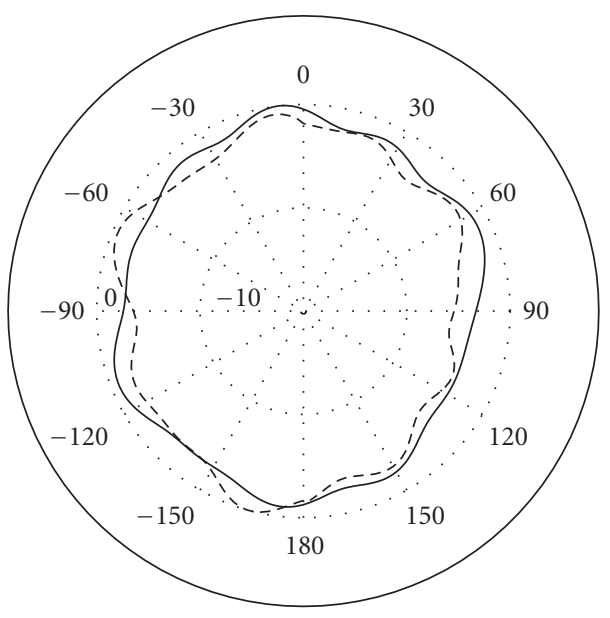

(c)

Figure 11: Measured (solid line) and simulated (dashed line) radiation patterns at $5 \mathrm{GHz}$ : (a) $x$-z plane, (b) $y$-z plane, and (c) $x-y$ plane.

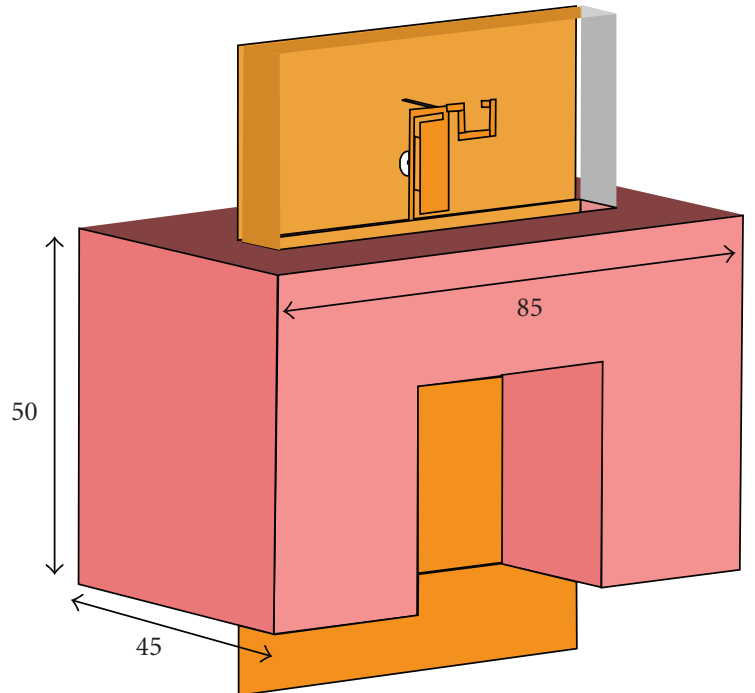

Figure 12: General view of the tri-band antenna with the proposed hand model.

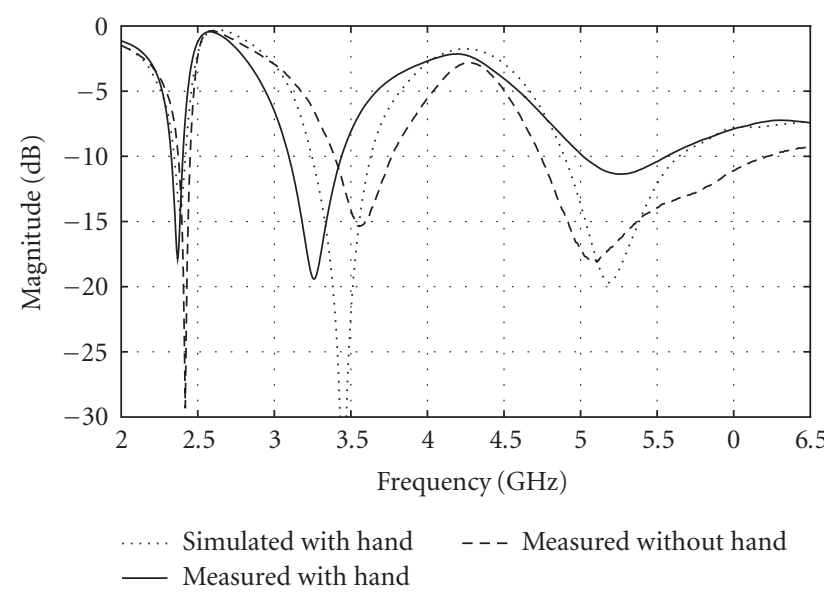

Figure 13: User's hand effect on the reflection coefficient of the proposed antenna.

corner of the PCB ground plane in order to accommodate the RF and signal processing modules.

3.3. Radiation Pattern Results. The radiation characteristics of the proposed antenna are measured in an anechoic chamber. The measured realized gain is shown in Figure 8 with the simulated one. It should be noted that there are no frequency points for the gain between $4 \mathrm{GHz}$ and $4.9 \mathrm{GHz}$. The maximum realized gain is still higher than $4 \mathrm{~dB}$ over the $3.5 \mathrm{GHz}$ and $5 \mathrm{GHz}$ bands. As for the first band, the measured gain equals $2 \mathrm{~dB}$.

The radiation patterns of the proposed antenna at the three resonance frequencies, $2.44 \mathrm{GHz}, 3.5 \mathrm{GHz}$, and $5 \mathrm{GHz}$ are illustrated in Figures 9, 10, and 11.

This antenna does not offer the same radiation pattern at the three resonance frequencies. 

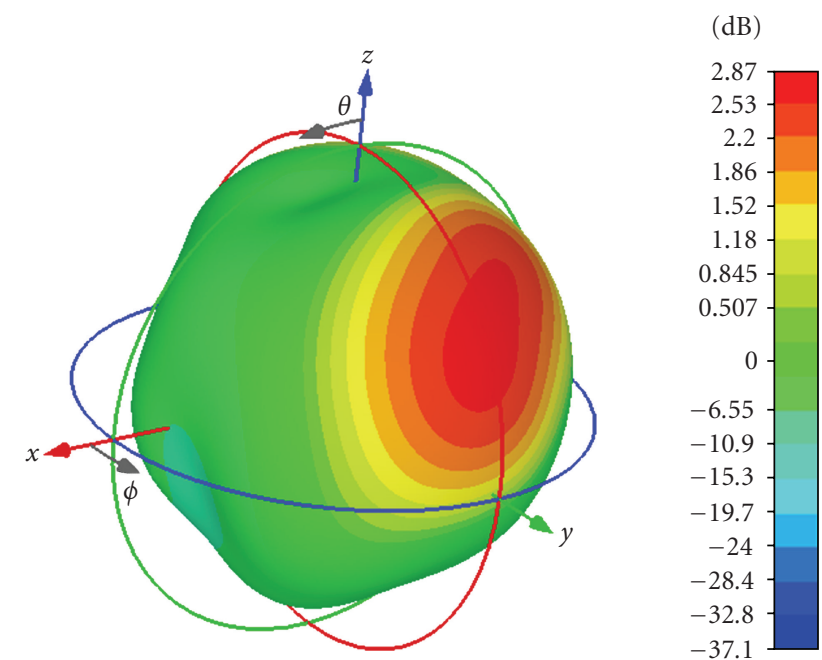

Figure 14: 3D simulated radiation patterns at $3.5 \mathrm{GHz}$ when the terminal is used in hand.

TABLE 1: Measured and simulated efficiency of the proposed antenna.

\begin{tabular}{lccc}
\hline Frequency $(\mathrm{GHz})$ & 2.44 & 3.5 & 5.5 \\
\hline Simulated total efficiency & $91 \%$ & $94 \%$ & $99 \%$ \\
Measured total efficiency & $75 \%$ & $90 \%$ & $95 \%$ \\
\hline
\end{tabular}

There is a good agreement between the measured and simulated results. The feeding cable is going behind the antenna during the measurements process and had no effect on the radiation patterns. Good omnidirectional radiation patterns at different frequencies were obtained in $x-y$ plane. The whole shapes of the radiation patterns are suitable for modern terminals.

Also, it should never be forgotten that the efficiency is an important parameter for small antennas. The measured and simulated efficiencies of the proposed antenna are shown in Table 1.

It is worth stating at this point that the efficiencies are obtained by dividing the measured directivity and the measured realized gain. This latter allows for ohmic losses, mismatch losses, connector losses, edge power losses, and external parasitic resonances. As for the directivity, it can be calculated by integrating the radiation patterns measured in a sufficient number of cutting planes [9].

So, there is a good agreement between the measured and simulated efficiencies except for the first band. This discrepancy at the first operating band is due to the difference in values between the measured and simulated reflection.

3.4. User's Hand Effects. It is undoubtedly true that the user's hand will affect the antenna performances. In this section, a simple hand model, shown in Figure 12, is used during the simulation. It is made up of several cubes of 35 relative permittivity, $0.5 \mathrm{~S} / \mathrm{m}$ conductivity, and $1000 \mathrm{Kg} / \mathrm{m}^{3}$ density [10]. The bottom radiating element edge and the top cube edge distance is important and is set to $5 \mathrm{~mm}$ in this case.
TABLE 2: Hand effect on the efficiency of the proposed antenna.

\begin{tabular}{lccc}
\hline Frequency $(\mathrm{GHz})$ & 2.44 & 3.5 & 5.5 \\
\hline Simulated efficiency without hand & $91 \%$ & $94 \%$ & $99 \%$ \\
Measured efficiency without hand & $75 \%$ & $90 \%$ & $95 \%$ \\
Simulated efficiency with hand & $41 \%$ & $54 \%$ & $60 \%$ \\
\hline
\end{tabular}

Figure 13 shows the hand effect on the antenna reflection coefficient.

It would appear, then, that the hand and its position affect the resonance frequencies. In fact, the two lower frequencies are decreased but in actual fact the tri-band antenna still operates at the three bands for any realistic position of the hand for $-6 \mathrm{~dB}$ impedance bandwidth definition. However, when the terminal is held by a hand, the total efficiency is reduced due to the hand's high permittivity over the three bands (Table 2).

It is obvious to everyone that the hand changes the radiation pattern of a handheld antenna due to its high permittivity. Figure 14 shows the $3 \mathrm{D}$ simulated radiation pattern at $3.5 \mathrm{GHz}$ when the terminal is used in hand. The maximum realized gain is $2.87 \mathrm{~dB}$ in the y direction.

\section{Conclusion}

A novel multiband antenna based on PIFA radiating element for multistandard terminals is proposed. An antenna prototype has been fabricated and tested. The good agreement obtained between experimental and numerical simulations results has validated the design procedure and the utility of such multistandard antenna. It has a $-10 \mathrm{~dB}$ impedance bandwidth over three bands and covering the WiFi bands $(3.6 \%$ at $(2.39-2.48 \mathrm{GHz})$ and $30 \%$ at $(4.7-6.3 \mathrm{GHz}))$ and WiMax band (11\% at $(3.36-3.76 \mathrm{GHz}))$ band. Also, the good radiation patterns at different frequencies make the proposed antenna suitable for use in modern handsets.

Even if the antenna is held by a hand at any real position, it still covers the three bands for $-6 \mathrm{~dB}$ impedance bandwidth definition. The small size of the proposed antenna shows that it is possible to place two radiating elements in the PCB's upper corners in order to increase the capacity in rich multipath environments thanks to MIMO techniques. Indeed, two identical antennas which are horizontally separated would be used to perform spatial antenna diversity applications. They will be placed at both PCB upper corners.

\section{References}

[1] T. Taga and K. Tsunekawa, "Performance analysis of a built-in planar inverted $\mathrm{F}$ antenna for $800 \mathrm{MHz}$ band portable radio units," IEEE Journal on Selected Areas in Communications, vol. 5, no. 5, pp. 921-929, 1987.

[2] M. A. Jensen and Y. Rahmat-Samii, "FDTD analysis of PIFA diversity antennas on a hand-held transceiver unit," in Proceedings of the Antennas and Propagation Society International Symposium, pp. 814-817, Dig Atlanta, Ga, USA, 1993.

[3] K. L. Virga and Y. Rahmat-Samii, "Low-profile enhanced$\mathrm{B}$ and width PIFA antennas for wireless communications 
packaging," IEEE Transactions on Microwave Theory and Techniques, vol. 45, no. 10, part 2, pp. 1879-1888, 1997.

[4] R. Hossa, A. Byndas, and M. E. Bialkowski, "Improvement of compact terminal antenna performance by incorporating open-end slots in ground plane," IEEE Microwave and Wireless Components Letters, vol. 14, no. 6, pp. 283-285, 2004.

[5] http://www.projet-oriana.fr/.

[6] P. Nepa, G. Manara, A. A. Serra, and G. Nenna, "Multiband PIFA for WLAN mobile terminals," IEEE Antennas and Wireless Propagation Letters, vol. 4, no. 1, pp. 349-350, 2005.

[7] Z. D. Liu, P. S. Hall, and D. Wake, "Dual-frequency planar inverted-f antenna," IEEE Transactions on Antennas and Propagation, vol. 45, no. 10, pp. 1451-1458, 1997.

[8] M. Manteghi and Y. Rahmat-Samii, "A novel miniaturized triband pifa for MIMO applications," Microwave and Optical Technology Letters, vol. 49, no. 3, pp. 724-731, 2007.

[9] J. S. Hollis, T. J. Lyon, and L. Clayton Jr., Eds., Microwave Antennas Measurements, Scientific Atlanta, Atlanta, Ga, USA, 1970.

[10] S. Gabriel, R. W. Lau, and C. Gabriel, "The dielectric properties of biological tissues: III. Parametric models for the dielectric spectrum of tissues," Physics in Medicine and Biology, vol. 41, no. 11, pp. 2271-2293, 1996. 

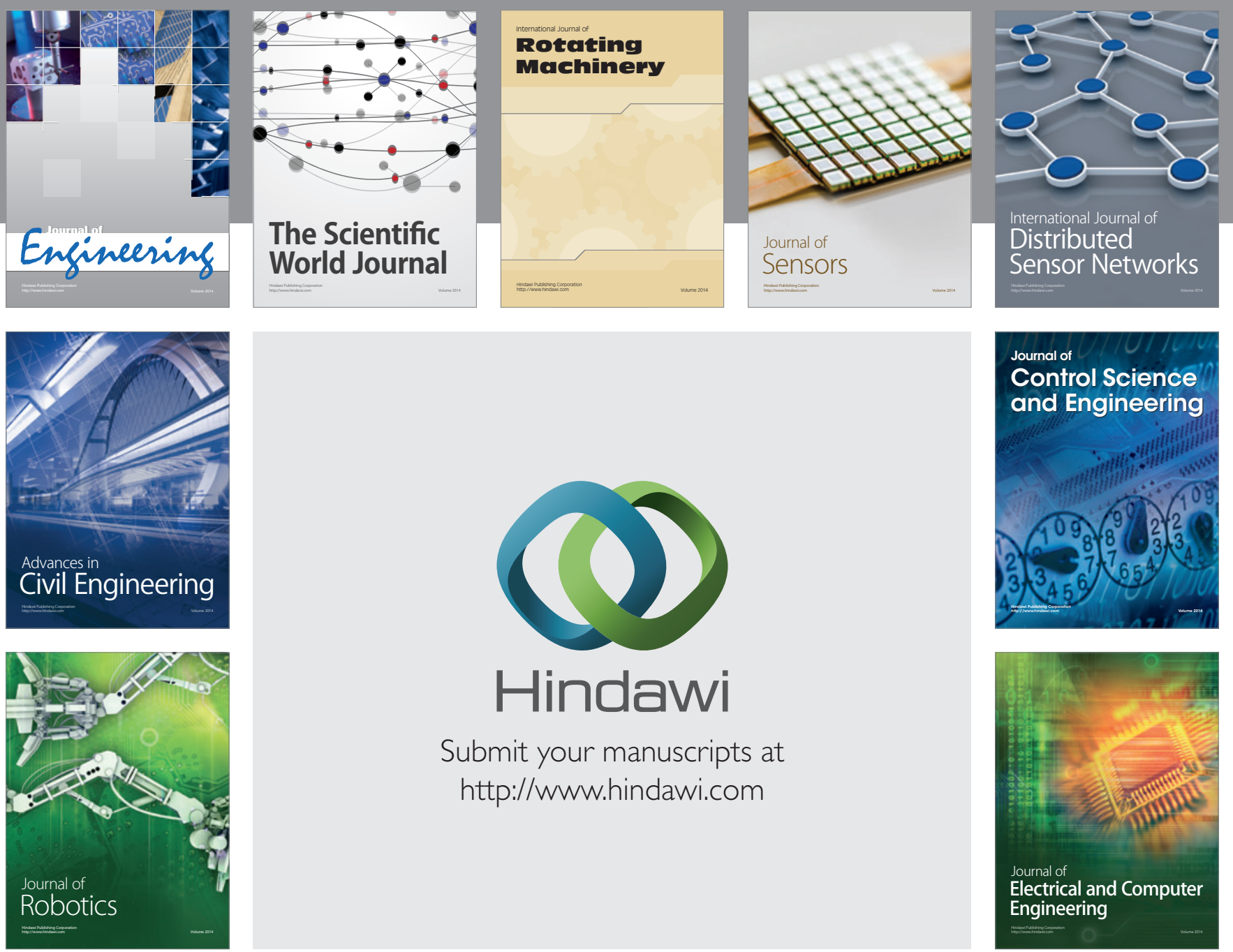

Submit your manuscripts at

http://www.hindawi.com
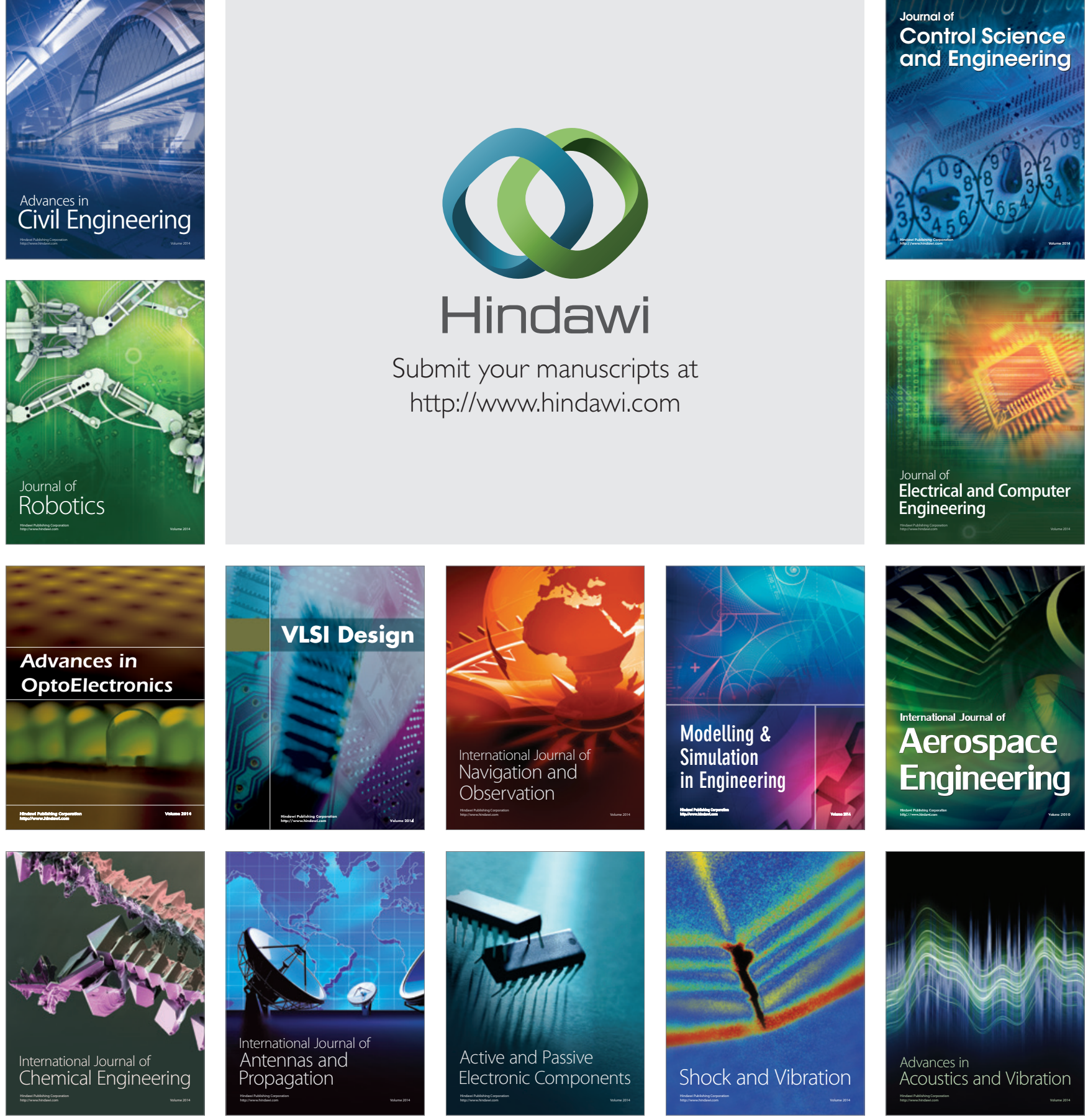